\title{
Effect of Chemotherapy on the Nutritional Status of Egyptian Patients with Breast Cancer
}

\author{
Soha M. Talima ${ }^{1}$, Lamia M. Nabil' ${ }^{2}$ Mahmoud H. El-Meghawry ${ }^{2}$ \\ ${ }^{1}$ Clinical Oncology Department, Kasr Al-Ainy Center of Clinical Oncology and Nuclear Medicine \\ (NEMROCK), Kasr Al-Ainy School of Medicine, Cairo University, Egypt., ${ }^{2}$ Medical Surgical \\ Department, Faculty of Nursing, Cairo University, Egypt.
}

Background: Chemotherapy and chemotherapy-related symptoms may greatly affect the nutritional status of the patient and reduces the quality of life.

Aim of the study: Assessment of the effect of chemotherapy on the nutritional status of breast cancer patients.

Methods: In this prospective observational study, we assessed the nutritional status of 60 breast cancer patients receiving chemotherapy by anthropometric measurements including body weight (BW), body mass index (BMI), triceps skin fold (TSF), and mid arm muscle circumference (MAMC). Symptoms related to chemotherapy were assessed with a yes/no questionnaire.

Results: Forty three patients (71\%) experienced weight loss during the course of treatment. Compared to baseline assessment before starting chemotherapy, there was a significant reduction in the average of all parameters at the end of chemotherapy. Body weight decreased from $78.97( \pm 9.6) \mathrm{kg}$ to $73.65( \pm 14.1) \mathrm{kg}, \mathrm{BMI}$ from $30.15( \pm 3.2) \mathrm{kg} /$ $\mathrm{m}^{2}$ to $28.01( \pm 4.8) \mathrm{kg} / \mathrm{m}^{2}$, TSF from $4.23( \pm 0.5) \mathrm{cm}$ to $3.97( \pm 0.68) \mathrm{cm}$ and MAMC from $36.31(4.02) \mathrm{cm}$ to 34.61 $( \pm 5.04) \mathrm{cm}(p<0.001$ for all). Significant reduction in BMI observed in patients who experienced alteration in taste especially those with taste alteration for $>1$ week $(p<0.001)$. Similarly, BMI reduction was significantly associated with loss of appetite and its duration $(p<0.001)$.

Conclusion: During chemotherapy, breast cancer patients are prone to lose weight particularly, those patients who experience taste alteration and appetite-loss for longer duration..

Key words: Breast cancer, Chemotherapy, Nutrition, Body mass index

Corresponding Author: Soha M. Talima, M.D, Clinical Oncology Department, Kasr Al-Ainy Center of Clinical Oncology and Nuclear Medicine (NEMROCK), Kasr Al-Ainy School of Medicine, Cairo University, Cairo 11562, Egypt, Email: soha_talima@hotmail.com

Submitted: 9-February-2017, Revised: 27-February-2017, Accepted: 7-March-2017

\section{INTRODUCTION}

Breast cancer is the commonest cancer in women account for about $23 \%$ of all cancer incidences ${ }^{1}$. Most of the patients who have early-stage disease receive adjuvant chemotherapy, radiotherapy and hormonal treatment before or after surgery with the aim of prevention of disease recurrence ${ }^{2}$. However, chemotherapy for breast cancer can result in multiple adverse effects such as nausea, vomiting, taste and smell changes, besides, loss of appetite that may interfere with proper dietary intake ${ }^{3}$.

Changes in food intake can affect the nutritional status of patients and may impact the disease prognosis. Evidence of weight changes from chemotherapy showed a worse prognosis for the cancer patient, both with weight gain and weight loss ${ }^{4,5}$.

Data are scarce regarding weight changes observed during chemotherapy in Egyptian breast cancer patients. We, therefore, performed this prospective study to evaluate weight changes during chemotherapy and the effect of chemotherapy related symptoms among a group of consecutive women with breast cancer treated at an Egyptian cancer center.

\section{METHODS}

\section{Ethical approval}

This prospective study was approved by the local institutional ethical committee. Written consents were obtained from patients after explanation of the nature and purpose of the study.

\section{Study design}

This is a prospective observational descriptive study conducted on breast cancer patients treated at Kasr AL-Ainy Center of Clinical Oncology and Nuclear Medicine (NEMROCK), Cairo University Hospitals and are scheduled to receive neoadjuvant or adjuvant chemotherapy for their disease. 


\section{Eligibility criteria}

For inclusion in the study, female patients should have stage I-III histologically confirmed invasive duct carcinoma and scheduled to receive neoadjuvant / adjuvant chemotherapy. The patient should be more than 18 years, free of comorbid diseases and have the physical, verbal and cognitive ability needed to respond to the tools necessary to data collection. All -patients were included before starting the first cycle of chemotherapy.

\section{Exclusion criteria}

Patients with primary tumor site other than the breast or metastatic disease were excluded. Moreover, patients not planned to receive chemotherapy or those who started first cycle before inclusion in the study were also excluded.

\section{Tools of data collection}

To collect data for this research, we used the following tools:

1. Structured questionnaire through interviewing:

The first part included socio- demographic variables such as age, occupation, level of education, marital status and income. The second part included medical data sheet which covered variables such as current medical diagnosis, staging of the disease, type of surgery, timing of chemotherapy and number and duration of chemotherapy sessions.

\section{Nutritional Assessment tools:}

Adopted from Jarvis ${ }^{6}$ and modified and translated by El Feky ${ }^{7}$. The modification needed, validity and reliability were done by experts in the field of Medical Surgical Nursing specialty, Faculty of Nursing Cairo University.

\section{Tools of assessment include:}

a. Anthropometric measurements that may be relevant measures of a cancer patient's nutritional status ${ }^{8}$ including; height, weight, body mass index (BMI), Triceps skin fold (TSF) and Mid-arm muscle circumference (MAMC).

The BMI was calculated by dividing weight by height squared $(\mathrm{kg} / \mathrm{m} 2)$. According to WHO standards, BMI categories were defined as: normal weight $(<25 \mathrm{~kg} /$ $\mathrm{m} 2$ ), overweight (25-30 kg/m2), obese ( $\geq 30 \mathrm{~kg} / \mathrm{m} 2)$, and underweight $(<18.5 \mathrm{~kg} / \mathrm{m} 2)^{9}$.

TSF which reflect fat mass was measured at the midpoint between the acromion and olecranon at the triceps muscle. MAMC which indicate the store of muscle protein was calculated using the formula:

MAMC $(\mathrm{cm})=$ MAC $(\mathrm{cm})-3.14 \times$ TSF $(\mathrm{cm})$ where MAC is Mid-arm circumference (MAC) was measured at the same level as $\mathrm{TSF}^{10}$.

The normal ranges of MAMC and TSF in females are as follow: $21.2-25 \mathrm{~cm}$ and $21-25 \mathrm{~mm}$, respectively ${ }^{10}$. b. Risk factors affecting nutritional status: it covers items answered by yes or no, including decreased appetite, taste alteration, nausea, vomiting.

c. Dietary assessment: This includes dietary

history and dietary habits.

\section{Procedure}

Data collection was carried out at three different times during the chemotherapy. The first assessment was completed before the first cycle of chemotherapy. The second assessment was after the intermediate cycle $\left(2^{\text {nd }}\right.$, $3^{\text {rd }}$, or $4^{\text {th }}$ cycles if the patient was planned to receive 4 , 6 or 8 cycles; respectively). Finally, the third assessment performed after the last cycle of chemotherapy.

\section{Statistical Analysis}

Data were statistically described in terms of mean \pm standard deviation ( \pm SD), median and range, or frequencies (number of cases) and percentages when appropriate. Correlation between various variables was done using Pearson moment correlation equation for linear relation in normally distributed variables and Spearman rank correlation equation for non-normal variables/non-linear monotonic relation. $p$ values less than 0.05 was considered statistically significant. All statistical calculations were done using computer program SPSS (Statistical Package for the Social Science; SPSS Inc., Chicago, IL, USA) release 15 for Microsoft Windows (2006).

\section{RESULTS}

A total of 60 patients were recruited in the period between March 2014 and July 2014. Characteristics of the study population are shown in Table 1.

Disease characteristics and treatment received are summarized in Table 2. Most of the patients had stage II disease. All the patients received combination chemotherapy with anthracycline based treatment either in the adjuvant setting $(78.3 \%)$ or in the neoadjuvant one $(21.7 \%)$. Among the study subjects, who received adjuvant chemotherapy, $43.3 \%$ had radical mastectomy and $35 \%$ had lumpectomy. Ninety-three percent of the patients received 8 cycles of anthracycline-taxanes containing treatment.

The results of the anthropometric assessments are illustrated in Table 3. Prior to chemotherapy, 97\% of patients were either overweight or obese. Moreover, TSF and MAMC parameters, both were above the normal range in the majority of patients. Seventy-one percent of our patients experienced weight loss during their treatment. During chemotherapy patients had progressive reduction in BMI, TSF and MAMC.

A comparison of the anthropometric measurements before versus after chemotherapy is shown in Table 4. The decrease in weight, BMI, TSF and MAMC was highly significant. 
Table 5 shows the gastrointestinal toxicities and dietary habits of our patients.

Decreased appetite occurred in $78.3 \%$ of the patients in the second assessment, of which $30 \%$ experienced decreased

Table 1: Socio-demographic characteristics of patients

\begin{tabular}{|c|c|c|}
\hline & No. & $\%$ \\
\hline \multicolumn{3}{|l|}{ Age } \\
\hline $20-<30$ & 3 & 5 \\
\hline $30-<40$ & 24 & 40 \\
\hline $40-\leq 50$ & 33 & 55 \\
\hline Mean \pm SD & $40.1 \pm 6.3$ & \\
\hline \multicolumn{3}{|l|}{ Marital status } \\
\hline Single & 3 & 5 \\
\hline Married & 53 & 88.3 \\
\hline Divorced & 2 & 3.3 \\
\hline Widow & 2 & 3.3 \\
\hline \multicolumn{3}{|l|}{ Occupation } \\
\hline Housewife & 55 & 91.7 \\
\hline Employed & 5 & 8.3 \\
\hline \multicolumn{3}{|l|}{ Education level } \\
\hline Illiterate & 9 & 15 \\
\hline$<$ high school & 32 & 53.3 \\
\hline High school & 13 & 21.7 \\
\hline University & 6 & 10 \\
\hline
\end{tabular}

Table 2: Disease characteristics and treatment.

\begin{tabular}{|c|c|c|c|}
\hline Variable & & No. & $\%$ \\
\hline \multicolumn{4}{|c|}{ Histological diagnosis } \\
\hline & Invasive duct carcinoma & 60 & 100 \\
\hline \multicolumn{4}{|l|}{ Stage } \\
\hline & II & 36 & 60 \\
\hline & III & 24 & 40 \\
\hline \multicolumn{4}{|l|}{ Surgery } \\
\hline & Modified radical mastectomy & 26 & 43.3 \\
\hline & Breast conservative surgery & 21 & 35 \\
\hline & None & 13 & 21.7 \\
\hline \multicolumn{4}{|c|}{ Length of hospital stay during surgery } \\
\hline & $<1$ week & 46 & 76.7 \\
\hline & $\geq 1$ week & 1 & 1.7 \\
\hline & None & 13 & 21.7 \\
\hline \multicolumn{4}{|c|}{ Time of chemotherapy administration } \\
\hline & Before surgery (neoadjuvant) & 13 & 21.7 \\
\hline & After surgery (adjuvant) & 47 & 78.3 \\
\hline \multicolumn{4}{|c|}{ Starting time of chemotherapy } \\
\hline & Without surgery & 13 & 21.7 \\
\hline & $<1$ month post-surgery & 40 & 66.7 \\
\hline & 1-2 months post-surgery & 7 & 11.7 \\
\hline \multicolumn{4}{|c|}{ Number of chemotherapy sessions } \\
\hline & 4 & 1 & 1.7 \\
\hline & 6 & 3 & 5 \\
\hline & 8 & 56 & 93.3 \\
\hline \multicolumn{4}{|c|}{ Duration and type of chemotherapy } \\
\hline & $\begin{array}{l}12 \text { weeks (Anthracycline - } \\
\text { Cyclophosphamide) }\end{array}$ & 1 & 1.7 \\
\hline & 18 weeks (Anthracycline -Taxane) & 3 & 5 \\
\hline & 24 weeks (Anthracycline -Taxane) & 56 & 93.3 \\
\hline
\end{tabular}

appetite for more than 1 week. This percent elevated to $81 \%$ in the third assessment. Also, taste alteration was experienced by $73.3 \%$ of the study subjects in the second assessment versus $83.3 \%$ in the third assessment.

Twenty nine patients representing $48.4 \%$ of the study subjects suffered from vomiting $>$ grade II (2-5 episodes of vomiting in a 24-hour) after chemotherapy in the $2^{\text {nd }}$ assessment. This percent decreased to $26.6 \%$ in the $3^{\text {rd }}$ assessment. In the $2^{\text {nd }}$ assessment, $61.7 \%$ had nausea that decreased to $33.3 \%$ in the $3^{\text {rd }}$ assessment.

Eighty-three percent of the participants had regular daily meals before starting chemotherapy; this percentage decreased to $16.7 \%$ in the 3 rd assessment. Moreover, the percentage of patients having 3 meals per day decreased from $85 \%$ in the 1 st assessment to $26.7 \%$ at the end of chemotherapy in the $3^{\text {rd }}$ assessment.

Table 6 shows a highly significant decrease in BMI in patients who experienced alteration in taste sensation. Participants with taste alteration for more than one week were at higher risk of weight-loss and BMI decrease. Loss of appetite had also a significant effect on loss of BMI at the end of the course of chemotherapy.

\section{DISCUSSION}

There is a debate on the effect of chemotherapy on weight gain in breast cancer patients with scarce data in Egyptians. This cross sectional study shows weight loss in the majority of patients with a significant decrease in BMI and other anthropometric measures after completing the course of chemotherapy. Changes in BW are valuable indicators of nutritional risk. In many cancer types, weight loss is an independent predictor of more toxicity from chemotherapy and shorter overall survival ${ }^{11}$. Another tool for nutrition status assessment of a cancer patient in clinical practice is the BMI-decrease ${ }^{12}$.

Based on the WHO classification of BMI, 97\% of our breast cancer patients were overweight/obese at presentation. By the end of chemotherapy, this percentage decreased significantly to $72 \%$ with a significant reduction in the mean BMI. Data on weight changes as a consequence of chemotherapy showed different results. Some trials reported weight gain during adjuvant chemotherapy in $50-96 \%$ of all breast cancer patients. The median weight increase ranged from 1 to $6 \mathrm{~kg}$ along the treatment course and follow-up periods of up to 1 year ${ }^{13,14,17}$. Noteworthy, trials that followed patients only through treatment have observed no weight gain ${ }^{15,16,18}$.

In a similar trial, 18 breast cancer patients were followed-up during chemotherapy and also for 1 year after completion of treatment 19. There was a lack of weight gain and even weight loss among the studied patients $^{19}$. The baseline mean weight of $64.5 \mathrm{~kg}$ decreased to $64.3 \mathrm{~kg}$ at mid treatment, which may be due to reduction of energy intake during the course of treatment. 
Table 3: Anthropometric measurements along the course of chemotherapy

\begin{tabular}{|c|c|c|c|c|c|c|}
\hline \multirow[t]{2}{*}{ Variables } & \multicolumn{2}{|c|}{$\begin{array}{c}1^{\text {st }} \text { assessment } \\
\text { (before the } 1^{\text {st }} \text { cycle) }\end{array}$} & \multicolumn{2}{|c|}{$\begin{array}{c}2^{\text {nd }} \text { assessment } \\
\text { (after the mid-cycle) }\end{array}$} & \multicolumn{2}{|c|}{$\begin{array}{c}3^{\text {rd }} \text { assessment } \\
\text { (after the last cycle) }\end{array}$} \\
\hline & No. & $\%$ & No. & $\%$ & No. & $\%$ \\
\hline \multicolumn{7}{|l|}{ Body mass index } \\
\hline Normal & 2 & 3.3 & 7 & 11.7 & 17 & 28.3 \\
\hline Overweight & 27 & 45 & 30 & 50 & 24 & 40 \\
\hline Obese & 31 & 51.7 & 23 & 38.3 & 19 & 31.7 \\
\hline Mean \pm SD & \multicolumn{2}{|c|}{$30.15 \pm 3.17$} & \multicolumn{2}{|c|}{$29.06 \pm 3.46$} & \multicolumn{2}{|c|}{$28.01 \pm 4.76$} \\
\hline \multicolumn{7}{|c|}{ Triceps skin fold (TSF) } \\
\hline Normal & 1 & 1.7 & 2 & 3.3 & 2 & 3.3 \\
\hline Above normal & 59 & 98.3 & 58 & 96.7 & 58 & 96.7 \\
\hline Mean \pm SD & \multicolumn{2}{|c|}{$04.23 \pm 0.5$} & \multicolumn{2}{|c|}{$04.08 \pm 0.59$} & \multicolumn{2}{|c|}{$03.97 \pm 0.68$} \\
\hline \multicolumn{7}{|c|}{ Mid-arm muscle circumference (MAMC) } \\
\hline Normal & 0 & 0 & 1 & 1.7 & 1 & 1.7 \\
\hline Above normal & 60 & 100 & 59 & 98.3 & 59 & 98.3 \\
\hline Mean $\pm \mathrm{SD}$ & \multicolumn{2}{|c|}{$36.31 \pm 4.02$} & \multicolumn{2}{|c|}{$35.48 \pm 4.33$} & \multicolumn{2}{|c|}{$34.61 \pm 5.04$} \\
\hline
\end{tabular}

Table 4: Comparison of the anthropometric parameters before versus after chemotherapy

\begin{tabular}{lccccc}
\hline \multirow{2}{*}{ Measurement } & \multicolumn{2}{c}{$\begin{array}{c}\mathbf{1}^{\text {st }} \text { assessment (before } \\
\text { chemotherapy) }\end{array}$} & \multicolumn{2}{c}{$\begin{array}{c}\mathbf{3}^{\text {rd }} \text { assessment (after } \\
\text { chemotherapy) }\end{array}$} & $p$ value \\
\cline { 2 - 6 } & Mean & SD & Mean & SD & \\
\hline Weight & 78.97 & 9.602 & 73.65 & 14.1 & $<0.001$ \\
\hline Body mass index (BMI) & 30.1 & 3.185 & 28.01 & 4.762 & $<0.001$ \\
\hline Triceps skin fold (TSF) & 4.24 & 0.504 & 3.97 & 0.683 & $<0.001$ \\
\hline Mid-arm muscle circumference (MAMC) & 36.31 & 4.04 & 34.62 & 5.04 & $<0.001$ \\
\hline
\end{tabular}

In a nonrandomized prospective study, Kutynec et al ${ }^{18}$ followed the patients up pre and post treatment. Body weight was obtained at baseline and after 12 weeks, whereas chemotherapy didn't result in weight gain ${ }^{18}$. On the other hand, Heideman et al reported significant weight gain during the year after diagnosis with a mean weight gain of $+2 \mathrm{~kg}^{13}$. Another trial performed by Irwin et al who assessed weight and body fat at baseline and after 2 years found an increase in weight by $1.7 \pm 4.7$ $\mathrm{kg}{ }^{20}$.

The discrepancy between previous researchers' results and ours may be attributed to the fact that previous trials followed the patients for at least one year after the end of chemotherapy. On the contrary, our study had a short follow up (24 weeks) during chemotherapy. Body weight and BMI during chemotherapy may be affected by decreased food intake as a result of chemotherapy related symptoms. Moreover, the majority (90\%) of our patients were $>30 \mathrm{BMI}$ at presentation, a group of patients may not be at a risk of developing weight gain. This is consistent with Nissen et al who reported that women of normal $\mathrm{BW}$ at the time of their breast cancer diagnosis are more prone to gain weight after chemotherapy than overweight or obese patients ${ }^{21}$.

Regarding other anthropometric measurements, the decrease in the mean TSF and MAMC also were evident at the end of chemotherapy denoting malnutrition among this group of patients.
Our research aimed to study the effect of chemotherapy on weight and BMI. In context, chemotherapy related side effects as nausea, vomiting and taste alteration may be a direct cause of weight loss in cancer patients and contribute to the deterioration of patients' nutritional status ${ }^{22}$. At the end of chemotherapy, the most frequent GI symptoms amongst our patients were decreased appetite $(81 \%)$, taste alteration $(83 \%)$ and nausea (33\%) and vomiting (27\%). A similar prevalence of GI symptoms was found in studies conducted by Lu et al who reported an incidence of taste changes (48.8\%) among a group of cancer patients receiving chemotherapy ${ }^{23}$. Alike, Ishikawa et al reported taste sensation affection in $44 \%$ of patients receiving chemotherapy and appetite loss in $87 \%{ }^{24}$.

Previous studies revealed that patients with cancer experience numerous symptoms, which commonly affect their food intake and many of them may start at the same time $^{25}$. Subsequently, we have expected weight loss and reduced BMI in patients experienced chemosensory symptoms that have been proven in our results. In our study, taste alteration was significantly associated with decreased BMI $(p=0.001)$, whereas taste alteration for more than one week greatly affected nutritional intake and accordingly resulted in reduction of the BMI $(p=0.001)$ calculated at the end of chemotherapy. On the other hand, BMI wasn't significantly affected by nausea and vomiting. 
Table 5: Gastrointestinal problems and dietary intake before, during and after the course of chemotherapy.

\begin{tabular}{|c|c|c|c|c|c|c|}
\hline \multirow[t]{2}{*}{ Variables } & \multicolumn{2}{|c|}{$\begin{array}{c}1^{\text {st }} \text { assessment (before the } 1^{\text {st }} \\
\text { cycle) }\end{array}$} & \multicolumn{2}{|c|}{$\begin{array}{c}2^{\text {nd }} \text { assessment (after the mid- } \\
\text { cycle) }\end{array}$} & \multicolumn{2}{|c|}{$\begin{array}{c}3^{\text {rd }} \text { assessment (after the last } \\
\text { cycle) }\end{array}$} \\
\hline & No. & $\%$ & No. & $\%$ & No. & $\%$ \\
\hline \multicolumn{7}{|l|}{ Decreased appetite } \\
\hline No & 60 & 100 & 13 & 21.7 & 11 & 18 \\
\hline Yes & 0 & 0 & 47 & 78.3 & 49 & 81 \\
\hline$<1$ week & 0 & 0 & 29 & 48.3 & 33 & 51.7 \\
\hline$>1$ week & 0 & 0 & 18 & 30 & 16 & 26.7 \\
\hline \multicolumn{7}{|l|}{ Taste alteration } \\
\hline No & 60 & 100 & 22 & 36.6 & 10 & 16.7 \\
\hline Yes & 0 & 0 & 44 & 73.3 & 50 & 83.3 \\
\hline$<1$ week & 0 & 0 & 10 & 13.6 & 5 & 10 \\
\hline$>1$ week & 0 & 0 & 34 & 59.7 & 45 & 90 \\
\hline \multicolumn{7}{|c|}{ Vomiting (> grade 2) } \\
\hline No & 60 & 100 & 31 & 51.6 & 44 & 73.4 \\
\hline Yes & 0 & 0 & 29 & 48.4 & 16 & 26.6 \\
\hline \multicolumn{7}{|l|}{ Nausea (> grade 2) } \\
\hline No & 60 & 100 & 23 & 38.3 & 40 & 66.7 \\
\hline Yes & 0 & 0 & 37 & 61.7 & 20 & 33.3 \\
\hline \multicolumn{7}{|l|}{ Meals intake } \\
\hline Regular & 50 & 83.3 & 14 & 23.3 & 10 & 16.7 \\
\hline Irregular & 10 & 16.7 & 46 & 76.6 & 50 & 83.3 \\
\hline \multicolumn{7}{|c|}{ Number of daily meals } \\
\hline $1-2$ & 9 & 15 & 39 & 65 & 42 & 70 \\
\hline 3 & 51 & 85 & 19 & 31.7 & 16 & 26.7 \\
\hline When hungry & 0 & 0 & 2 & 3.3 & 2 & 3.3 \\
\hline
\end{tabular}

Moreover, most of the chemotherapy cycles contained taxane as part of the chemotherapy course, which was previously accused to alter taste sensation ${ }^{26}$. In 2009 Steinbach and colleagues studied taste and smell changes in patients with breast and gynecologic cancer receiving chemotherapy. They found that taste and smell are significantly affected by chemotherapy, which resulted in reduced appetite and weight loss. And Taxanebased chemotherapy caused the most severe disorders ${ }^{26}$. Furthermore, Speck et al evaluated the effect of taxanes on patients received docetaxel or paclitaxel and reported taste alteration as the most common side effect from taxanes ${ }^{27}$.

Our study was limited by the small number of patients and the short follow up of the weight gain after chemotherapy.

\section{RECOMMENDATIONS}

Based on our findings, the nutritional assessment of breast cancer patients should be carried out prior to chemotherapy. Attention towards nutritional problems related to chemotherapy is needed. To prevent massive weight loss, patients should maintain adequate energy intake during the course of chemotherapy. Besides, a long-term follow-up of weight changes after the end of the course of chemotherapy is also recommended.

Future research on larger number of patients with longer follow up is required to assess the nutritional status of patients receiving chemotherapy for breast cancer to avoid nutritional deficiency.

\section{REFERENCES}

1. International Agency for Research on Cancer. Latest world cancer statistics: Global cancer burden rises to 14.1 million new cases in 2012: Marked increase in breast cancers must be addressed. Lyon, France: World Health Organization, 2013.

2. Paluch-Shimon S, Pagani O, Partridge AH, et al. Second international consensus guidelines for breast cancer in young women (BCY2). Breast 2016; 26: 87-99.

3. Bernhardson BM, Tishelman C, Rutqvist LE. Self-reported taste and smell changes during cancer chemotherapy. Support Care Cancer. 2008; 16(3): 275-283.

4. Makari-Judson G, Braun B, Jerry DJ, Mertens WC. Weight gain following breast cancer diagnosis: implication and proposed mechanisms. World J Clin Oncol. 2014; 5(3): 272-282. 
Table 6: Correlation between selected variables and the change in body mass index (BMI).

\begin{tabular}{|c|c|c|c|}
\hline \multirow{2}{*}{ Variable } & \multicolumn{2}{|c|}{ Change in BMI $\left(\mathrm{kg} / \mathrm{m}^{2}\right)$} & \multirow{2}{*}{$p$ value } \\
\hline & Mean & SD & \\
\hline \multicolumn{4}{|l|}{ Altered taste ( $2^{\text {nd }}$ assessment $)$} \\
\hline Yes & -3.39 & 2.78 & \multirow[t]{2}{*}{$<0.001$} \\
\hline No & 4.46 & 1.65 & \\
\hline \multicolumn{4}{|l|}{ Altered taste duration ( $2^{\text {nd }}$ assessment) } \\
\hline 0 & 4.46 & 1.65 & \multirow[t]{3}{*}{$<0.001$} \\
\hline$<1$ week & -3.16 & 2.85 & \\
\hline$\geq 1$ week & -3.85 & 2.68 & \\
\hline \multicolumn{4}{|l|}{ Altered taste ( $3^{\text {rd }}$ assessment) } \\
\hline Yes & -3.39 & 2.78 & \multirow[t]{2}{*}{$<0.001$} \\
\hline No & 4.46 & 1.65 & \\
\hline \multicolumn{4}{|l|}{ Altered taste duration ( $3^{\text {rd }}$ assessment) } \\
\hline 0 & 4.46 & 1.65 & \multirow[t]{3}{*}{$<0.001$} \\
\hline$<1$ week & -3.1 & 2.97 & \\
\hline$\geq 1$ week & -3.84 & 2.48 & \\
\hline \multicolumn{4}{|l|}{ Decreased appetite ( $2^{\text {nd }}$ assessment) } \\
\hline Yes & -3.83 & 2.19 & \multirow[t]{2}{*}{$<0.001$} \\
\hline No & 4.25 & 1.64 & \\
\hline \multicolumn{4}{|c|}{ Decreased appetite duration ( $2^{\text {nd }}$ assessment) } \\
\hline 0 & 4.25 & 1.64 & \multirow[t]{3}{*}{$<0.001$} \\
\hline$<1$ week & -3.57 & 2.66 & \\
\hline$\geq 1$ week & -4.25 & 0.99 & \\
\hline \multicolumn{4}{|l|}{ Decreased appetite ( $3^{\text {rd }}$ assessment) } \\
\hline Yes & -3.83 & 2.19 & \multirow[t]{2}{*}{$<0.001$} \\
\hline No & 4.25 & 1.64 & \\
\hline \multicolumn{4}{|c|}{ Decreased appetite duration ( $3^{\text {rd }}$ assessment) } \\
\hline 0 & 4.25 & 1.64 & \multirow[t]{3}{*}{$<0.001$} \\
\hline$<1$ week & -3.52 & 2.58 & \\
\hline$\geq 1$ week & -4.44 & 0.9 & \\
\hline \multicolumn{4}{|l|}{ Acute nausea ( $2^{\text {nd }}$ assessment) } \\
\hline Yes & -2.53 & 3.41 & \multirow[t]{2}{*}{0.264} \\
\hline No & -1.36 & 4.67 & \\
\hline \multicolumn{4}{|l|}{ Delayed nausea ( $2^{\text {nd }}$ assessment) } \\
\hline Yes & -1.52 & 4.13 & \multirow[t]{2}{*}{0.118} \\
\hline No & -3.21 & 3.36 & \\
\hline \multicolumn{4}{|l|}{ Vomiting ( $2^{\text {nd }}$ assessment) } \\
\hline Yes & -2.56 & 3.82 & \multirow[t]{2}{*}{0.337} \\
\hline No & -1.57 & 4.07 & \\
\hline Vomiting ( $3^{\text {rd }}$ assessment) & & & \\
\hline Yes & -3.17 & 3.49 & 0.202 \\
\hline No & -1.69 & 4.06 & \\
\hline & & orrelation & p value \\
\hline Vomiting frequency ( $2^{\text {nd }}$ assessment) & -0.087 & & 0.511 \\
\hline Vomiting frequency ( $3^{\text {rd }}$ assessment) & -0.229 & & 0.079 \\
\hline
\end{tabular}


5. Marinho LA, Rettori O, Vieira-Matos AN. Body weight loss as an indicator of breast cancer recurrence. Acta Oncol. 2001; 40(7): 832-837.

6. Jarvis G. Physical Examination and Health Assessment. Philadelphia: WB. Saunders Co, 1996; pp: 126-151.

7. El- Feky H. Relationship of Nutritional Status: Wound Healing and Hospital Stay among General Surgical Patients at El-Manial University Hospital. Unpublished Master Thesis, Faculty of Nursing, Cairo University; 2001.

8. Bollag D, Genton L, Pichard C. Assessment of nutritional status. Ann Med Interne (Paris). 2000; 151(7): 575-583.

9. BMI Classification. WHO Global Database on Body Mass Index. World Health Organization. 2014. Available from: http://apps.who.int/bmi/ index.jsp?introPage=intro_3. html.

10. Symreng T. Arm anthropometry in a large reference population and in surgical patients. Clin Nutr. 1982; 1(3): 211-219.

11. Gregg JR, Cookson MS, Phillips S, et al. Effect of preoperative nutritional deficiency on mortality after radical cystectomy for bladder cancer. J Urol. 2011; 185(1): 90-96.

12. Sarhill N, Mahmoud FA, Christie R, Tahir A. Assessment of nutritional status and fluid deficits in advanced cancer. Am J Hosp Palliat Care. 2003; 20(6): 465-473.

13. Heideman WH, Russell NS, Gundy C, Rookus MA, Voskuil DW. The frequency, magnitude and timing of post-diagnosis body weight gain in Dutch breast cancer survivors. Eur J Cancer. 2009; 45(1): 119-126.

14. Rock CL, Flatt SW, Newman V, et al. Factors associated with weight gain in women after diagnosis of breast cancer. Women's Healthy Eating and Living Study Group. J Am Diet Assoc. 1999; 99(10): 1212-1221.

15. Aslani A, Smith RC, Allen BJ, Pavlakis N, Levi JA. Changes in body composition during breast cancer chemotherapy with the CMF-regimen. Breast Cancer Res Treat. 1999; 57(3): 285-290.

16. Ingram $\mathrm{C}$, Brown JK. Patterns of weight and body composition change in premenopausal women with early stage breast cancer has weight gain been overestimated? Cancer Nurs. 2004; 27(6): 483-490.

17. Chlebowski RT, Aiello E, McTiernan A. Weight loss in breast cancer patient management. J Clin Oncol. 2002; 20(4): 1128-1143
18. Kutynec CL, McCargar L, Barr SI, Hislop TG. Energy balance in women with breast cancer during adjuvant treatment. J Am Diet Assoc. 1999; 99(10): 1222-1227.

19. Demark-Wahnefried W, Hars V, Conaway MR, et al. Reduced rates of metabolism and decreased physical activity in breast cancer patients receiving adjuvant chemotherapy. Am J Clin Nutr. 1997; 65(5): 1495-1501.

20. Irwin ML, McTiernan A, Baumgartner RN, et al. Changes in body fat and weight after a breast cancer diagnosis: influence of demographic, prognostic, and lifestyle factors. J Clin Oncol. 2005; 23(4): 774-782.

21. Nissen MJ, Shapiro A, Swenson KK. Changes in weight and body composition in women receiving chemotherapy for breast cancer. Clin Breast Cancer. 2011; 11(1): 52-60.

22. Bosaeus I. Nutritional support in multimodal therapy for cancer cachexia. Support Care Cancer. 2008; 16(5): 447451.

23. Lu J, Ma L, Wang X, Liu Z, Wang J, Li K. Screening for prodromes of chemotherapy-induced vomiting and correlation between prodromes and chemotherapy-induced vomiting in lung cancer patients. Zhonghua Zhong Liu Za Zhi. 2014; 36(7): 511-515.

24. Ischikawa, T, Morita J, Kawachi K, Tagashira H. Incidence of dysgeusia associated with chemotherapy for cancer. GanTo Kagaku Ryoho. 2014; 40(8): 1049-1054.

25. Grosvenor M, Bulcavage L, Chlebowski RT. Symptoms potentially influencing weight loss in a cancer population: correlations with primary site, nutritional status and chemotherapy administration. Cancer. 1989; 63(2): 330-334.

26. Steinbach S, Hummel T, Bohner C, et al. Qualitative and quantitative assessment of taste and smell changes in patients undergoing chemotherapy for breast cancer or gynecologic malignancies. J Clin Oncol. 2009; 27(11): 1899-1905.

27. Speck RM, DeMichele A, Farrar JT, et al. Taste alteration in breast cancer patients treated with taxane chemotherapy: experience, effect, and coping strategies. Support Care Cancer. 2013; 21(2): 549-555. 